\title{
N-2-chloroethyl-N-ethyl-2-bromobenzylamine hydrochloride (DSP4), a new selective noradrenaline neurotoxin, and taste neophobia in the rat
}

\author{
TREVOR ARCHER, SVEN-OVE OGREN, and SVANTE B. ROSS \\ Research and Development Laboratories, Astra Lakemedel AB, 15185 Södertälje, Sweden
}

\begin{abstract}
Rats were systemically injected with N-2-chloroethyl-N-ethyl-2-bromobenzylamine (DSP4), a selective noradrenaline neurotoxin, and their initial, neophobic response to a novel saccharin solution was measured. No significant alteration of the neophobic response was noted unless the novel saccharin was presented within a novel drinking bottle; then the DSP4treated rats showed a significantly attenuated neophobia, as measured by drinking suppression ratios. The discrepancy between the present findings, which range from no alteration to an attenuated neophobia, and the enhanced neophobia result of a previous investigation that used 6-hydroxydopamine is explained on the basis of the different methods employed for depleting brain noradrenaline.
\end{abstract}

The involvement of noradrenaline (NA) neurons in fear and anxiety reactions has been indicated (Huang, Redmond, Snyder, \& Maas, 1975; Mason \& Fibiger, 1979a; Redmond, Huang, Snyder, \& Maas, 1976), but the extent of this involvement is at present not unequivocally accepted (Fibiger \& Mason, 1978; Mason \& Fibiger, 1977, 1978, 1979b). One simple test for fear reactions in the rat involves the animal's initial response to novel stimuli. Neophobic responses to novel taste substances (Barnett, 1956; Domjan \& Bowman, 1974; Green \& Parker, 1974) and to novel environmental stimuli (Carrol, Dinc, Levy, \& Smith, 1975; Jennings \& McCutcheon, 1974; Mitchell, Kirschbaum, \& Perry, 1975) have been amply discussed elsewhere (Domjan, 1977; Mitchell, 1976). If NA neurons play a role in the rat's initial fear of novel stimuli, then it is to be expected that the consumption of a novel taste, following degeneration of NA nerve terminals, will be altered. To deplete forebrain NA, Mason, Roberts, and Fibiger (1978) used intracerebral injections of 6-hydroxydopamine (6OHDA) into the ascending NA neurons of the dorsal noradrenaline bundle (DB) derived from the locus coeruleus (LC). Later, following recovery, their lesioned rats displayed a significantly decreased saccharin intake, which was interpreted as inceased neophobia to the novel taste. Since the Mason et al. (1978) finding is not consistent with predictions concerning the hypothesized role of NA in fear (Huang et al., 1975; Redmond et al., 1976), the application of other tools to deplete forebrain NA may provide

Reprints may be obtained from Trevor Archer, Astra Lakemedel AB, S-151 85 Södertälje, Sweden. a means of gaining further insight into the involvement of the locus coeruleus NA system (LC-DB system) in fear and anxiety reactions (neophobia). Therefore, to establish the extent of NA involvement in taste neophobia, four experiments were performed with a new selective neurotoxin which causes a degeneration of NA neurons in brain regions (Jonsson, Ponzio, \& Ross, 1978; Ross, 1976).

Following systemic injection, N-2-chloroethyl-Nethyl-2-bromobenzylamine hydrochloride (DSP-4), has been shown to produce long-term reduction of NA and dopamine $\beta$-hydroxylase (DBH) in the rat brain and inhibition of the neuronal uptake of NA in rat and mouse brain (Ross, 1976; Ross \& Renyi, 1976; JaimEtcheverry \& Zieher, 1980). When injected into rats (50 mg/kg, ip), DSP4 caused a marked reduction in the capacity of brain homogenates prepared from rat forebrain regions to accumulate NA up to 8 months following treatment (Ross, 1976). These effects indicate degeneration of NA neurons, which has been verified by histochemical experiments (Jonsson, 1980; Jonsson et al., 1978; and unpublished observations). Pretreatment of the animals with the NA uptake inhibitor desipramine counteracts the neurotoxic effect of DSP4. The peripheral NA neurons appear to be affected less by DSP4 than are the central NA neurons, since the decrease in NA concentrations in the rat heart was recovered rapidly after $50 \mathrm{mg} / \mathrm{kg}$ ip of DSP4 and was about $75 \%$ of that of the controls 4 days after the injection (Jaim-Etcheverry \& Zieher, 1980; Ross, 1976). Furthermore, the DBH activity in the rat heart was not influenced, which indicates that the sympathetic nerves in the heart, at least, were not degenerated (Ross, 1976). The con- 
centrations of the catecholamines in the rat adrenals were not significantly changed (unpublished observations).

\section{METHODS}

\section{Subjects}

All 129 subjects were male Sprague-Dawley rats (Anticimex AB, Sollentuna, Sweden). Those used in Experiments 1, 3, and 4 were 50-55 days old and weighed approximately $225 \mathrm{~g}$ (range 200-250 g) at the beginning of the experiments. The animals used in Experiment 2 were $85-90$ days old and weighed approximately $390 \mathrm{~g}$ (range 360-410 g). Within each experiment, all groups were matched for body weight. All animals received at least a 2-week period of acclimatization to laboratory conditions. They were kept throughout on a 12-h-on/12-h-off lighting schedule (lights on at $0600 \mathrm{~h}$ ) in a room thermostatically maintained at $21 \pm 1^{\circ} \mathrm{C}$. Adlib food (lab chow R3, Astra-Ewos, Södertälje, Sweden) was available throughout. Water, in glass bottles with nozzles $2 \mathrm{~mm}$ wide at the tip, was freely available during the acclimatization period.

\section{Behavioral Treatment}

Table 1 indicates the various conditions and treatments manipulated in Experiments 1-4. Following acclimatization, on the treatment day (Day 1), the rats in each of the five experiments were injected ip with either DSP4 $(50 \mathrm{mg} / \mathrm{kg}$, dissolved in distilled water) or saline $(5 \mathrm{ml} / \mathrm{kg})$. In Experiment 2 , the specific NA uptake inhibitor, desipramine (DMI, $10 \mathrm{mg} / \mathrm{kg}$ ) was administered $20 \mathrm{~min}$ prior to DSP4 in the "DMI+DSP4" condition (see Table 1, column 3). In Experiment 3, a lithium chloride ( $\mathrm{LiCl}, .15 \mathrm{M}$, ip) control group for "enhanced neophobia" was treated at the same time as the DSP4 group. Water was freely available for 1 day following injections, after which the water bottles were removed and the rats in all experiments, except Experiment 3, were placed on a 23-h water-deprivation schedule; in Experiment 3, a 23.5-h water-deprivation schedule was maintained. Thus, all animals received 5 days of training to a $60-\mathrm{min} /$ day $(30 \mathrm{~min} /$ day in the case of Experiment 3) water-drinking regime. The water intake data from the last day of the water-deprivation schedule, that is, Day 8 , were recorded as the water intake baseline (see Table 1, column 4).

\section{Saccharin Presentation}

On Day 9, 60- or 30-min (Experiment 3) saccharin (.2\%) presentations were delivered either from the same type of drinking bottle that the rats had used throughout (Experiments 1, 2, and 3; see Table 1) or from novel noise-producing bottles, "noisy" bottles (Ehret, West Germany), that had metal nozzles with a 6-mm hole at the tip and contained two small metal balls which created a considerable amount of noise when the animals licked the tips of the nozzles (Experiment 4, see Table 1). The intake of saccharin and water was measured to the nearest $1.0 \mathrm{~g}$.

\section{Biochemical Treatment}

After completion of the behavioral experiments, the animals in Experiment 2 were taken for analysis of catecholamine concentrations in the cortex, the hippocampus, and the rest of the brain excluding the cerebellum. In separate experiments with the same design as that of Experiment 2, the NA and DA content was determined in the cortex, hippocampus, and hypothalamus. Following decapitation, the regions were rapidly dissected on ice and stored at $-70^{\circ} \mathrm{C}$ until analysis. After homogenization and centrifugation, the homogenates were purified on a strongly acidic cation-exchange column (Dowex $50 \mathrm{~W}-\mathrm{X}-4$ ) (for details, see Atack \& Magnusson, 1978). After elution, NA and DA were analyzed by fluorometry (Amino-Bowman spectrofluorometer).

\section{RESULTS}

\section{Behavioral}

Table 1 shows the median water and saccharin intake, as well as the median DSRs (see below) for each of the groups in Experiments 1-4. All groups treated with DSP4 7 days prior to the water intake test (Day 8) showed a clear reduction in water intake. This finding was replicated in all four experiments. In addition, the group pretreated with desipramine (DMI+DSP4) seems to have blocked this deficit in water intake. It seems reasonable to conclude (1) that DSP4 treatment exerted a long-term detrimental effect on water intake, and (2) that DMI $(10 \mathrm{mg} / \mathrm{kg})$ tended to block the DSP4 effect on water drinking. Absolute saccharin intake by the DSP4 rats was also lower than that of control animals in all experiments; this deficit reached significance only in Experiments 1,3 , and 4 (see Table 1 , column 5 ). In contrast, rats that were treated with lithium chloride 1 week prior to the water and saccharin intake tests showed no such deficit. Nonspecific enhanced neophobic effects may therefore be ruled out.

As a measure of the neophobic response to the novel saccharin solution (Experiments 1-3) and to the novel saccharin + "noisy" bottle (Experiment 4), we

Table 1

Median Water and Saccharin Intake Values and Median Drinking Suppression Ratios in Experiments 1-4

\begin{tabular}{|c|c|c|c|c|c|c|}
\hline Experiment & $\begin{array}{c}\text { Novel Exteroceptive } \\
\text { Cue Presented }\end{array}$ & $\begin{array}{l}\text { Treatment } \\
\text { Group }\end{array}$ & $\begin{array}{c}n \\
\text { (Day 1) }\end{array}$ & $\begin{array}{l}\text { Water Intake } \\
\text { (Day 8) }\end{array}$ & $\begin{array}{l}\text { Saccharin Intake } \\
\text { (Day 9) }\end{array}$ & DSR \\
\hline 1 & None & $\begin{array}{l}\text { DSP4 } \\
\text { Saline }\end{array}$ & $\begin{array}{l}8 \\
8\end{array}$ & $\begin{array}{l}13.5^{*} \\
20.5\end{array}$ & $\begin{array}{l}15.0^{* *} \\
17.5\end{array}$ & $\begin{array}{c}1.00 \dagger \\
.85\end{array}$ \\
\hline 2 & None & $\begin{array}{l}\text { DSP4 } \\
\text { DMI + DSP4 } \\
\text { Saline }\end{array}$ & $\begin{array}{l}12 \\
15 \\
16\end{array}$ & $\begin{array}{l}16.0 \\
19.0^{* *} \\
21.0^{*}\end{array}$ & $\begin{array}{l}16.0 \dagger \\
16.0 \\
17.0\end{array}$ & $\begin{array}{c}1.00 \dagger \\
.84 \dagger \\
.80\end{array}$ \\
\hline 3 & None & $\begin{array}{l}\text { DSP4 } \\
\text { LiCl } \\
\text { Saline }\end{array}$ & $\begin{array}{l}8 \\
8 \\
8\end{array}$ & $\begin{array}{c}8.5 \\
17.5^{*} \\
16.0^{*}\end{array}$ & $\begin{array}{l}6.5 \\
11.5 * * \\
12.5 *\end{array}$ & $\begin{array}{l}.82 \\
.69 \dagger \\
.77 \dagger\end{array}$ \\
\hline 4 & "Noisy" Bottle & $\begin{array}{l}\text { DSP4 } \\
\text { Saline }\end{array}$ & $\begin{array}{l}34 \\
12\end{array}$ & $\begin{array}{l}17.0^{*} \\
24.5\end{array}$ & $\begin{array}{l}14.0^{* *} \\
17.0\end{array}$ & $\begin{array}{l}.87^{*} \\
.75\end{array}$ \\
\hline
\end{tabular}

Note-Median DSRs consist of ratios between amounts drunk on Day 8 (saccharin) and Day 7 (water) presentations for individual animals. Significance levels are based on Mann-Whitney U tests. $\quad * p<.01 . \quad * * p<.05 . \quad$ †Nonsignificant. 
Table 2

Postmortem Amine Assays on Animals Used in Experiment 2 and in Two Separate Experiments

Experiment 2

\begin{tabular}{|c|c|c|c|c|c|c|c|c|c|c|c|c|c|c|c|c|c|c|c|c|c|}
\hline & & & \multicolumn{9}{|c|}{ Hippocampus-Cortex (Two-Pooled $n=4$ ) } & \multicolumn{10}{|c|}{ Rest of Brain $(n=8)$} \\
\hline & & & \multicolumn{5}{|c|}{ NA } & \multicolumn{4}{|c|}{ DA } & & \multicolumn{4}{|c|}{ NA } & \multicolumn{5}{|c|}{ DA } \\
\hline & & & $\mathrm{N}$ & & Q & $\%$ & & M & & Q & $\%$ & & M & $\mathrm{Q}$ & & $\%$ & M & & Q & $\%$ & \\
\hline \multirow{3}{*}{\multicolumn{3}{|c|}{$\begin{array}{l}\text { Saline } \\
\text { DSP } 4 \\
\text { DMI + DSP } 4\end{array}$}} & & 50 & 12 & & & 32 & & 4 & & & 590 & 32 & & & $137\}$ & & 17 & & \\
\hline & & & & 22 & $2^{*}$ & 9 & & 33 & & 4 & 103 & & 231 & $20^{*}$ & & 39 & 139 & & 67 & 101 & \\
\hline & & & & 98 & $17 \dagger$ & 39 & & 24 & & 5 & 75 & & 360 & $19^{*}$ & & 61 & 125 & & 47 & 91 & 1 \\
\hline \multicolumn{17}{|c|}{$\begin{array}{l}\text { Separate Experiment I } \\
\qquad(\mathrm{n}=6)\end{array}$} & \multicolumn{5}{|c|}{$\begin{array}{l}\text { Separate Experiment II } \\
\qquad(n=6)\end{array}$} \\
\hline & \multicolumn{5}{|c|}{ Cortex } & \multicolumn{6}{|c|}{ Hippocampus } & \multicolumn{5}{|c|}{ Hypothalamus } & \multicolumn{5}{|c|}{ Adrenal Gland } \\
\hline & \multicolumn{3}{|c|}{ NA } & \multicolumn{2}{|c|}{ DA } & \multicolumn{3}{|c|}{ NA } & \multicolumn{3}{|c|}{ DA } & \multicolumn{3}{|c|}{ NA } & \multicolumn{2}{|c|}{ DA } & \multicolumn{2}{|c|}{ NA } & \multicolumn{3}{|c|}{$\mathbf{A}$} \\
\hline & M & $\mathrm{Q}$ & $\%$ & $M \quad Q$ & $\%$ & M & Q & $\%$ & $\mathbf{M}$ & Q & $\%$ & $\mathbf{M}$ & Q & $\%$ & M & $\mathrm{Q} \%$ & M & Q & $\mathbf{M}$ & Q & $\%$ \\
\hline $\begin{array}{l}\text { Saline } \\
\text { DSP } 4\end{array}$ & $\begin{array}{r}179 \\
17\end{array}$ & $\begin{array}{l}34.0 \\
2.5^{*}\end{array}$ & 9 & $\begin{array}{ll}33 & 6 \\
47 & 3\end{array}$ & 142 & $\begin{array}{r}144.00 \\
.01\end{array}$ & $\begin{array}{l}20 \\
6 *\end{array}$ & 0 & $\begin{array}{l}27.0 \\
53.5\end{array}$ & $\begin{array}{r}7 \\
32\end{array}$ & 196 & $\begin{array}{r}1790 \\
927\end{array}$ & $\begin{array}{c}134 \\
82^{*}\end{array}$ & 52 & $\begin{array}{l}454 \\
441\end{array}$ & $\begin{array}{ll}48 & \\
31 & 97\end{array}$ & $\begin{array}{l}153 \\
101\end{array}$ & $\begin{array}{l}4 \\
4 * 6\end{array}$ & $\begin{array}{ll} & 348 \\
56 & 286\end{array}$ & $\begin{array}{l}32 \\
13\end{array}$ & 121 \\
\hline
\end{tabular}

Note-Values are median $(M) \pm$ quartiles $(Q) N A$ and DA concentrations, expressed as nanograms of amine per gram of tissue. DSP 4 $(50 \mathrm{mg} / \mathrm{kg})$ was injected intraperitoneally; DMI $(10 \mathrm{mg} / \mathrm{kg})$ was injected 20 min prior to the DSP 4 injection. The Experiment 2 rats were sacrificed 22 days after DSP 4 treatment and, in the separate experiments, 7 days after treatment. \%= percent values of control. Significance levels are based on Mann-Whitney U tests. $\quad{ }^{*} p<.001 . \quad t_{p}<.02$.

computed drinking suppression ratios (DSRs) (cf. Archer \& Sjödén, 1979a, 1979b; Lyon, 1968), as the ratios of the amounts of Day 9 saccharin to Day 8 water consumed by individual rats (see Table 1, column 6). There was a distinct trend by which the DSRs of the DSP4 rats exceeded that of the controls and "DMI + DSP4" -treated rats. This trend, however, did not reach significance in any of the first three experiments. Prior $\mathrm{LiCl}$ treatment failed to produce any "enhanced neophobia." Mann-Whitney U tests (Siegel, 1956), comparing DSP4-treated groups with control groups, indicated a significant DSP4 $>$ control difference in Experiment 4. In all four experiments, DSP4treated rats tended to show greater DSRs. Thus, we may conclude that, in general, rats pretreated with DSP4 may demonstrate some attenuation of their neophobic response to a novel taste. This attenuation is more pronounced when that taste is presented in conjunction with a novel exteroceptive cue. Prior treatment with DMI $(10 \mathrm{mg} / \mathrm{kg})$ appears to block this effect.

\section{Biochemical}

Table 2 shows the NA and DA concentrations of brain regions in 24 of the animals used in Experiment 2. DSP4-treatment $(50 \mathrm{mg} / \mathrm{kg})$ produced a drastic depletion of NA both in the cortex-hippocampus regions ( $9 \%$ of control values) and in the rest of the brain $(39 \%)$. Pretreatment with desipramine $(10 \mathrm{mg} /$ $\mathrm{kg}$ ip) partially, but significantly, protected from the marked depletion of NA in the cortex-hippocampus region (39\%) and the rest of the brain (61\%). DSP4 treatment did not alter the DA content in the cortex+ hippocampus and in the rest of the brain. In a separate study, DSP4 $(50 \mathrm{mg} / \mathrm{kg})$ caused a marked reduction of NA in the cortex $(9 \%)$ and in the hippocampus $(0 \%)$. The hypothalamic NA was less affected $(52 \%)$. The content of DA was not significantly changed in these three brain regions, although there was a clear trend for an increase in DA content noted in both the cortex and hippocampus. Biochemical data from a second separate experiment (II) indicate a partial, but significant, depletion of NA as a result of DSP4 treatment, but no effect upon adrenaline (A).

\section{DISCUSSION}

Several aspects of the data from the present experiments require consideration: (1) DSP4-treated rats typically consumed less water than controls 1 week following treatment; pretreatment with DMI $(10 \mathrm{mg} /$ $\mathrm{kg}$ ) seems to block this effect. (2) DSP4-treated animals also demonstrated a distinct tendency to consume less of a novel saccharin solution; there was evidence that the DMI $(10 \mathrm{mg} / \mathrm{kg})$ pretreatment blocked this effect. (3) The DSRs, which take into account both water and saccharin intake of individual animals in providing a measure of "taste neophobia" (cf. Archer \& Sjödén, 1979a, 1979b), of DSP4-treated rats tended in all experiments to exceed that of the saline-treated rats, the former tended to show a lesser degree of neophobia to the novel taste and exteroceptive cue than did the latter.

Since DSP4 produces a simultaneous decrease in dopamine $\beta$-hydroxylase activity, concentration of NA, and accumulation of NA in frontal cortex, it was suggested that DSP4 degenerates noradrenergic nerve terminals (Ross, 1976). Jonsson et al. (1978, Jonsson, 1980 , and unpublished observations) have confirmed 
that DSP4 is a selective NA neurotoxin degenerating nerve terminals emanating from the locus coeruleus without any effect on dopamine or adrenaline. It has no long-term blocking effects on noradrenergic $\alpha$ and $\beta$ receptors. Although DSP4 $(50 \mathrm{mg} / \mathrm{kg}$ ip) in rats also influences peripheral NA neurons, the effect, at least in the heart, is short-lasting, since the decrease in the NA concentration was only about $25 \% 4$ days after the administration (Jaim-Etcheverry \& Zieher, 1980; Ross, 1976). The observation that DBH was not decreased in the heart indicates that the sympathetic nerve terminals in this organ were not degenerated (Ross, 1976). The adrenal catecholamine concentrations were not influenced by DSP4 at the dose employed in this study (see Table 2). It may be suggested that the action of DSP4 on the peripheral sympathetic nervous system contributes to the effect of DSP4 on taste neophobia observed in the present study. As discussed above, this action of DSP4 is much shorter lasting than is that upon central noradrenergic systems and is largely overcome 3 to 4 days after the DSP4 treatment. The experiments were performed 8 days after DSP4 administration. Although a peripheral contribution can obviously not be completely ruled out, the state of our present knowledge of DSP4 is such that this possibility is very unlikely. Further experiments with a quaternary uptake inhibitor, for example, imipramine methiodide, which antagonizes only the peripheral effect of DSP4, or with the aziridinium derivative of DSP4, which does not pass the blood brain barrier but, according to Zieher and Jaim-Etcheverry (1980), has peripheral neurotoxic action, might elucidate this question. Desipramine injected before DSP4 antagonizes the neurotoxic effects, which indicates that DSP4 requires a functionally active NA transport carrier for its action. Thus, parenterally injected DSP4 appears to be a useful tool for studies of the functional role of noradrenaline in the brain, inasmuch as specificity can be tested by pretreatment of the animals with desipramine.

The findings of Mason et al. (1978) indicate that NA-depleted rats show a greater neophobic avoidance of both novel tastes and a novel environment. The present DSR-data may be interpreted in terms of a lesser or attenuated neophobic avoidance of novel saccharin, but this was to a large extent dependent upon whether it was presented in a familiar water bottle or in a novel one. Although the contradictory results of the present study are not readily reconcilable with those of the Mason et al. (1978) study, two general procedural differences are apparent. First, the above authors used absolute saccharin intake as their measure of taste neophobia, whereas we used DSRs, that is, the ratio between saccharin and water intake to correct for water intake by individual rats. Mason et al. did measure baseline water intake and, in contrast to the present study, found no differences between the dorsal bundle (DB) lesioned and control animals. Different dependent variables cannot therefore explain the Mason et al. (1978) enhanced neophobic and our attenuated neophobic effects. It must be emphasized that in both studies, Mason et al.'s and ours, a decreased saccharin intake was observed in the context of a considerably decreased water intake. The discrepancy hinges upon the water intake data, and this poses something of a procedural dilemma. If absolute saccharin intake is accepted as the dependent variable, our results confirm those of Mason et al. (1978). Archer and Sjödén (1979a, 1979b) developed the DSR as a correction for individual differences in water intake prior to the presentation of a novel taste substance. Thus, it is reasonable to conclude that the DSR is especially useful in instances in which there are large between-group differences in baseline water intake. We have assumed, on the basis of previous results (Archer \& Sjödén, 1979a, 1979b), that DSRs offer a more reliable dependent variable for measuring neophobia.

It is possible that the discrepant results depend on the two tools employed to degenerate NA neurons. In the Mason et al. (1978) study, rats were selectively NA depleted through microinjections of the neurotoxin 6-hydroxydopamine (6-OHDA) into the dorsal bundle. It is apparent that the discrepancy between the finding of the present study, which used systematically injected DSP4, and the 6-OHDA study is not due to the extent of NA depletion in the forebrain. Both DSP4 and bilateral 6-OHDA injection in the dorsal bundle reduced NA concentration in the cortex and hippocampus to less than $10 \%$ of control values. Note that the extent of NA depletion is not identical in all regions. Thus, the dorsal bundle lesioned animals in the Mason study evidenced a more marked reduction of NA in the hypothalamus (approximately $70 \%$ as opposed to $48 \%$ in the present study). To attempt an explanation of the water intake differences between DSP4 and 6-OHDA treated rats on the basis of hypothalamic NA depletion can only be speculative. Osumi, Oishi, Fujiwara, and Takaori (1975) found a significant increase in water drinking following lesions of the locus coeruleus (LC) in DB which lowered the NA content of several regions of the forebrain, with the exception of the hypothalamus. Considering the fact that several subsequent studies have not indicated any changes in water intake (Koob, Sessions, Kant, \& Meyerhoff, 1976; Mason \& Iversen, 1978; Sessions, Kant, \& Koob, 1976), the role of hypothalamic NA in water intake is not well understood. The general consensus is that the LC-DB system plays a rather insignificant role with regard to fluid intake (Clark, 1979). DSP4 experiments have repeatedly demonstrated a marked deficit by the treated rats.

DSP4 treated rats showed a slightly, but significantly, lower neophobia, as reflected by a significantly higher DSR, only in the conditions in which a novel bottle cue was presented in conjunction with 
the novel taste (Experiment 4). In the absence of the novel "noisy" bottle, the difference between the DSP4 and control rats did not reach significance. The introduction of an increasing number of novel environmental stimuli in conjunction with a novel taste stimulus results in the progressively lower intake of the novel taste substance (Archer \& Sjödén, 1979a, 1979b) and allows for the possibility of manipulating exteroceptive and gustatory stimuli within the same behavioral situation. Consistent with those prior results, the present authors found a noticeably greater neophobic suppression of saccharin intake by both the control and DSP4 treated animals. The DSRs of the control rats were somewhat greater than those of untreated rats (Archer, unpublished observations); this could be explained by the prior handling that the former received (cf. Weinberg, Smotherman, \& Levine, 1978). Although it seems reasonable to conclude that there may exist a NA involvement in taste neophobia, further investigation of the neophobic response of NA-depleted rats to several other environmentally based stimuli (e.g., odor, animal compartment, lighting, handling) warrants further consideration.

Thus, it is concluded that NA may only to a limited extent be involved in fear reactions of the rat, as determined by a taste neophobia procedure. Our findings do not support the contention that NA depletion leads to an enhanced expression of fear (Mason \& Fibiger, 1977; Mason et al., 1978). If anything, the present data imply a direction more in keeping with that suggested by Huang et al. (1976) and Redmond et al. (1975) and suggest a decrease in the initial fear reaction when NA activity is decreased. Taste neophobia represents a primitive behavioral reaction that offers the rat considerable advantages in adapting to its environment (Galef \& Osborne, 1978; Mitchell, 1976). From an ecological viewpoint, these advantages would be squandered if only one particular neuronal system (e.g., NA) exerted a primary effect. Thus, until further, more elucidating evidence appears, we tentatively suggest some NA involvement in this particular behavioral expression of fear.

\section{REFERENCES}

Archer, T., \& SJödén, P. O. Neophobia in taste-aversion conditioning: Individual differences and effects of contextual changes. Physiological Psychology, 1979, 7, 364-369. (a)

Archer, T., \& Suödén, P. O. Positive correlation between preand postconditioning saccharin intake in taste-aversion learning. Animal Learning \& Behavior, 1979, 7, 144-148. (b)

Atack, C., \& Magnusson, T. A procedure for the isolation of noradrenaline (together with adrenaline), dopamine, 5-hydroxytryptamine and histamine from the same tissue sample using a single column of strongly acidic cation exchange resin. Acta Pharmacology and Toxicology, 1978, 42, 35-37.

BARNetT, S. A. Behaviour components in the feeding of wild and laboratory rats. Behaviour, 1956, 9, 24-43.
Carroll, M. E., Dinc, H. I., Levy, C. J., \& Smith, J. C. Demonstration of neophobia and enhanced neophobia in the albino rat. Journal of Comparative and Physiological Psychology, $1975,89,457-467$.

CLARK, T. K. The locus coeruleus in behaviour regulation: Evidence for behaviour-specific versus general involvement. Behavioural and Neural Biology, 1979, 25, 271-300.

Domjan, M. Attenuation and enhancement of neophobia for edible substances. In L. M. Barker, M. R. Best, \& M. Domjan (Eds.), Learning mechanisms in food selection. Waco, Tex: Baylor University Press, 1977.

Domjan, M., \& Bowman, T. G. Learned safety and the CS-VS delay gradient in taste-aversion learning. Learning and Motivation, 1974, 5, 409-423.

Fibiger, H. C., \& MAson, S. T. The effects of dorsal bundle injections of 6-OHDA on avoidance responding in rats. British Journal of Pharmacology, 1978, 64, 601-606.

Galef, B. G., \& Osborne, B. Novel taste facilitation of the association of visual cues with toxicosis in rats. Journal of Comparative and Physiological Psychology, 1978, 92, 907-916.

Green, K. F., \& PARKer, L. A. Gustatory memory: Incubation and interference. Behavioral Biology, 1975, 13, 359-367.

Huang, Y. H., Redmond, D. E., Snyder, D. R., \& Maas, T. W. In vivo location and destruction of the locus coeruleus in the stumptail macaque (Macaca arctoides). Brain Research, 1975, $100,157-162$.

Jaim-Etcheverry, G., \& Zieher, L. M. DSP4: A novel compound with neurotoxic effects on noradrenergic neurons of adult and developing rats. Brain Research, 1980, 188, 513-523.

Jennings, W. A., \& McCutcheon, L. E. Novel foods and novel running wheels: Conditions for inhibition of sucrose intake in rats. Journal of Comparative and Physiological Psychology, 1974, 87, 100-105.

Jonsson, G. Chemical neurotoxins as denervation tools in neurobiology. Annual Review of Neuroscience, 1980, 3, 169-187.

Jonsson, G., Ponzio, F., \& Ross, S. A new neurotoxic compound as denervation tool for noradrenaline neurons. 7th International Congress of Pharmacology. Paris, 1978. (Abstract 2810, p. 926)

Коов, G. F. Sessions, G. R., Kant, G. J., \& Meyerhoff, J. L. Dissociation of hyperdipsia from destruction of locus coeruleus in rats. Brain Research, 1976, 116, 339-345.

LyoN, D. O. Conditioned suppression: Operant variables and aversive control. Psychological Record, 1968, 18, 317-338.

Mason, S. T., \& Fibiger, H. C. Altered exploratory behavior after 6-OHDA lesion to the dorsal noradrenergic bundle. Nature (London), 1977, 269, 704-705.

Mason, S. T., \& Fibiger, H. C. Evidence for a role of brain noradrenaline in attention and stimulus sampling. Brain Research, 1978, 159, 421-426.

Mason, S. T., \& Fibiger, H. C. Noradrenaline and avoidance learning in the rat. Brain Research, 1979, 161, 321-333. (a)

Mason, S. T., \& Fibiger, H. C. Noradrenaline, fear and extinction. Brain Research, 1979, 165, 47-56. (b)

Mason, S. T., \& Iversen, S. D. Reward, attention and the dorsal adrenergic bundles. Brain Research, 1978, 150, $135-148$.

Mason, S. T., Roberts, D. C. S., \& Fibiger, H. C. Noradrenaline and neophobia. Physiology \& Behavior, 1978, 21, 353-361.

Mitchell, D. Experiments on neophobia in wild and laboratory rats: A reevaluation. Journal of Comparative and Physiological Psychology, 1976, 90, 190-197.

Mitchele, D., Kirschbaum, E. H., \& Perry, R. L. Effects of neophobia and habituation on the poison-induced avoidance of exteroceptive stimuli in the rat. Journal of Experimental Psychology: Animal Behavior Processes, 1975, 104, $47-55$.

Osumi, Y., Oishi, R., Fujiwara, H., \& Takaori, S. Hyperdipsia induced by bilateral destruction of the locus coeruleus in rats. Brain Research, 1975, 86, 419-427.

Redmond, D. E., Huang, Y. H., Snyder, D. R., \& MaAs, J. W. The behavioral effects of stimulation of the locus coeruleus in 
the stumptail monkey (Macaca arctoides). Brain Research, 1976, 116, 502-510.

Ross, S. B. Long-term effects of N-(2-chloroethyl)-N-ethyl-2bromobenzylamine hydrochloride on noradrenergic neurons in the rat brain and heart. British Journal of Pharmacology, 1976, 58, 521-527.

Ross, S. B., \& RENYI, A. L. On the long-lasting inhibitory effect of $\mathrm{N}$-(2-chloroethyl)-N-ethyl-2-bromobenzylamine (DSP4) on the active uptake of adrenaline. Journal of Pharmaceutical Pharmacology, 1976, 28, 458-459.

Sessions, G. R., Kant, G. J., \& КоOв, G. F. Locus coeruleus lesions and learning in the rat. Physiology \& Behavior, 1976, 17, 853-859.
Siegel, S. Nonparametric statistics. New York: McGraw-Hill, 1956.

Weinberg, J., Smotherman, W. S., \& Levine, S. Early handling effects on neophobia and conditioned taste aversions. Physiology \& Behavior, 1978, 20, 589-596.

ZiehER, L. M., \& JAIM-ETcheverRy, G. Neurotoxicity of N(2-chloroethyl)-N-ethyl-2-bromobenzylamine hydrochloride (DSP4) on noradrenergic neurons is mimicked by its cyclic aziridinium derivative. European Journal of Pharmacology, $1980,65,249-256$.

(Received for publication June 11, 1980; revision accepted February 18,1981 .) 